\title{
Diversity of Fusarium spp. associated with dry rot of potato tubers in Poland
}

\author{
Emil Stefańczyk • Sylwester Sobkowiak • \\ Marta Brylińska • Jadwiga Śliwka
}

Accepted: 26 January 2016/Published online: 3 February 2016

(C) The Author(s) 2016. This article is published with open access at Springerlink.com

\begin{abstract}
Fusarium spp. belong to the division Ascomycota and cause important plant diseases; these fungi may contaminate food products with mycotoxins, endangering human and animal health. Several Fusarium spp. have been associated with potato dry rot. The most frequent and devastating of these species are $F$. sambucinum, $F$. solani and F. oxysporum, depending on the geographic location and the season. Samples of potato tubers with dry rot symptoms were collected, and their putative fungal isolates were identified as Fusarium species using partial nucleotide sequences of the internal transcribed spacer, translation elongation factor $1-\alpha$ and $\beta$-tubulin genes. Among 149 isolates, 12 species were identified. $F$. oxysporum was the most frequent ( $45 \%$ of the isolates), followed by $F$. avenaceum (12.1\%), F. solani $(10.7 \%)$ and F. sambucinum (7.4\%). Phylogenetic analyses confirmed the species identifications and revealed a high diversity of $F$. solani and a low diversity of $F$. oxysporum. Potential producers of zearalenone and trichothecenes were identified within the obtained isolates using PCR markers. Isolates that
\end{abstract}

Electronic supplementary material The online version of this article (doi:10.1007/s10658-016-0875-0) contains supplementary material, which is available to authorized users.

E. Stefańczyk $\cdot$ S. Sobkowiak $\cdot$ M. Brylińska $\cdot$

J. Śliwka $(\bowtie)$

Plant Breeding and Acclimatization Institute - National Research Institute, Młochów Research Center, Platanowa 19,

05-831 Młochów, Poland

e-mail: j.sliwka@ihar.edu.pl were pathogenic to potatoes in laboratory tests were found in four species: F. sambucinum, $F$. avenaceum, $F$. culmorum, and F. graminearum. The effects of increased temperature and mixed inoculum on the pathogenicities of chosen species were evaluated. This study adds 434 potato-derived Fusarium sequences to the NCBI GenBank database and demonstrates that the list of Fusarium species and mycotoxins present in potato tubers may be richer than previously believed, regardless of whether these species cause dry rot or live as saprophytes.

Keywords ITS $\cdot$ mycotoxin $\cdot$ pathogenicity $\cdot$ Solanum tuberosum $\cdot$ tef- $1 \alpha \cdot \beta$-tubulin

\section{Introduction}

Potato (Solanum tuberosum L.) is a member of the Solanaceae family and is a highly nutritious crop grown worldwide. Potatoes are particularly valued in developing countries as a rich source of starch, vitamins $\mathrm{C}$ and B6 and essential amino acids. In 2013, over 376 million tons of potatoes were produced worldwide (FAOSTAT 2014) and stored for various lengths of time to provide a continuous supply of this staple food to consumers and industry. During long-term storage, potato tubers are vulnerable to many diseases. Possible injuries to the potato skin during harvesting can lead to, among other problems, potato dry rot, a disease caused by species of the genus Fusarium (Nelson et al. 1981). Dry rot, characterized by variously coloured cavities and hard, wrinkled skin, causes yield losses of up to $60 \%$ during 
storage (Theron 1991), with average losses of 6 to $25 \%$ (Chełkowski 1989).

Fusarium spp. belong to the division Ascomycota and occur in asexual and sexual (perfect) states. The discovery of perfect state can result in a species receiving a new genus and species name, which may cause confusion in the nomenclature. Fusarium species exhibiting such perfect stages belong to the genera Calonectria de Not., Gibberella Sacc., and Nectria Fries (Nelson et al. 1981), but these species are generally better known by their imperfect state names. Sexual states of many Fusarium have not yet been discovered and maybe never will, since some of them appear to have lost their ability for sexual reproduction (Nelson et al. 1981). A single-name system proposed by Geiser et al. (2013) unified the current usage of the name Fusarium and is used in this work.

The Fusarium spp. that colonize potato tubers vary depending on geographic location and time of the survey. F. sambucinum was the species most frequently isolated from potato tubers among eight species recovered in 1992-1993 in northeastern USA (Hanson et al. 1996), but also more recently in China (Du et al. 2012). F. oxysporum was reported to be the primary agent responsible for potato dry rot amidst 11 species in Michigan, USA (Gachango et al. 2012) and South Korea (Kim and Lee 1994). F. avenaceum dominated potato Fusarium population investigated between 1997 and 2000 in Scotland (Choiseul et al. 2007), while F. solani var. coeruleum dominated in four regions of Great Britain, including eastern Scotland, in 2000-2002 (Peters et al. 2008a). Globally, 13 Fusarium species are associated with potato dry rot (Cullen et al. 2005). However, this list can be extended to include $F$. ciliatum, F. reticulatum, F. torulosum and F. verticillioides (Kim and Lee 1994; Choiseul et al. 2007; Gachango et al. 2012) and most likely is still not complete. The pathogenicities of Fusarium spp. to potatoes differ considerably (Peters et al. 2008b) and the presence of less pathogenic species on dry rot-infected tubers might be opportunistic.

Dry rot in potato not only reduces the crop yield but can also contaminate the tubers with mycotoxins that cause cyto-, geno-, neuro- and hepatotoxic effects in animals and humans and thus threaten health when eaten directly (in Fusarium-infected plants) or indirectly (in the milk or meat of animals that have been fed with infected feed). The major types of mycotoxins produced by Fusarium spp. include beauvericin, moniliformin, fumonisins, trichothecenes and zearalenone, with the latter two considered the most important due to their common occurrence. Trichothecenes are produced by F. culmorum, F. graminearum, F. poae, F. cerealis, F. langsethiae, F. sporotrichioides and F. sambucinum, among other species (Nicholson et al. 2004), and zearalenone is produced by F. culmorum, F. graminearum, F. cerealis and F. equiseti (Stępień 2013). The potential to produce mycotoxins might be established by confirmation of the presence of Tri cluster (trichothecenes) and PKS (polyketide synthases) genes (zearalenone; Baturo-Cieśniewska and Suchorzyńska 2011). However, PCR-based assays are only a weak indicator of potential to produce mycotoxins. The actual production of mycotoxins is a complex process involving many enzymes and diverse mutations of genes coding these enzymes or their regulators may affect the final mycotoxin profile of the fungal strain. Many of these mutations may be not detected by simple PCR markers. Moreover, the production of mycotoxins may change depending on environmental conditions (Mateo et al. 2002) and the susceptibility of a given potato cultivar (Xue et al. 2014).

The biological role of Fusarium spp. in potato tubers either as dry rot agents, secondary pathogens or saprophytes is difficult to estimate, because even within species considered as the dry rot agents, non-pathogenic isolates were found and isolates of different species cause lesions of different sizes, i.e. isolates of F. sambucinum have caused significantly larger lesions than the isolates of other tested species (Gachango et al. 2012). In potato dry rot samples, Fusarium isolates that are non-pathogenic to potato in the laboratory assessment are frequently identified (Peters et al. 2008a; Peters et al. 2008b). Therefore, it is interesting to know which species are present in potato tubers regardless of their role, so the risk of possible mycotoxin contamination can be estimated.

Knowledge of the present European Fusarium population that is attacking potatoes is limited. Only one survey investigated Central Europe (Latus-Ziętkiewicz et al. 1987). According to this study, in 1985-86, F. sambucinum Fuckel was the main pathogen causing dry rot in Poland. Other reports have focused on intraspecific studies of certain Fusarium species, e.g., F. culmorum (Baturo-Cieśniewska and Suchorzyńska 2011), F. equiseti (Stępień et al. 2012) and F. sambucinum (BaturoCieśniewska et al. 2014).

The objectives of the present study were to: (1) identify the Fusarium species isolated from dry rot- 
infected potato tubers using the ITS (internal transcribed spacer), tef-1 $\alpha$ (translation elongation factor 1- $\alpha$ ) and bTub ( $\beta$-tubulin) genes; (2) evaluate their pathogenicities; (3) investigate their intraspecific diversity; and (4) examine the toxigenic potentials of the obtained isolates.

\section{Materials and methods}

Sampling and isolation of pure fungal cultures

Potato tubers with dry rot symptoms were collected in 2012-2014 from central (Chwałowice, Młochów, Zazdrość), western (Naroczyce, Świebodzin) and northern locations in Poland (Zamarte). The exact dates of isolation and descriptions of the potato stocks from which the isolates were extracted are listed in Supplementary Table 1 . Together, 14 potato cultivars were sampled grown from 13 independent seed stocks. Cultivar Denar was grown in two locations: Chwałowice and Młochów in 2012, cv. Jelly was grown in Młochów in 2010 and in Świebodzin 2013 and the remaining 12 cultivars were planted only once (Supplementary Table 1). Each cultivar sample consisted of 10 dry rot infected tubers that yielded from one to five Fusarium isolates, each one from a different tuber. 101 Fusarium spp. isolates were recovered from breeding lines. Different breeding lines were grown in Chwałowice, Młochów, Naroczyce and Zamarte, each one only at one location. Breeding lines were at the early stage of breeding and grown in the places of origin, providing information about Fusarium population associated with locations but not with the stock. Additionally, fungi were isolated from three imported potato tubers exhibiting disease symptoms that were bought in a local grocery store. We also included one isolate of unknown origin that was isolated in 1999 and 24 collected in 2011 from potatoes grown in Młochów. A total of 149 Fusarium isolates were analysed (Supplementary Table 1).

To obtain pure fungal cultures, $0.5 \times 0.5 \times 0.5 \mathrm{~cm}$ fragments of the tuber were taken from the borders of the healthy and diseased tissues and then disinfected in $70 \%$ ethanol and $0.1 \%$ mercuric chloride. The inoculum was rinsed in a sterile water and further incubated at $16{ }^{\circ} \mathrm{C}$ on potato sucrose agar (PSA) medium (Zarzycka 2001, modified). The conidia from a developed Fusarium colony were preselected via microscopic observations and spread on a thin layer of water agar

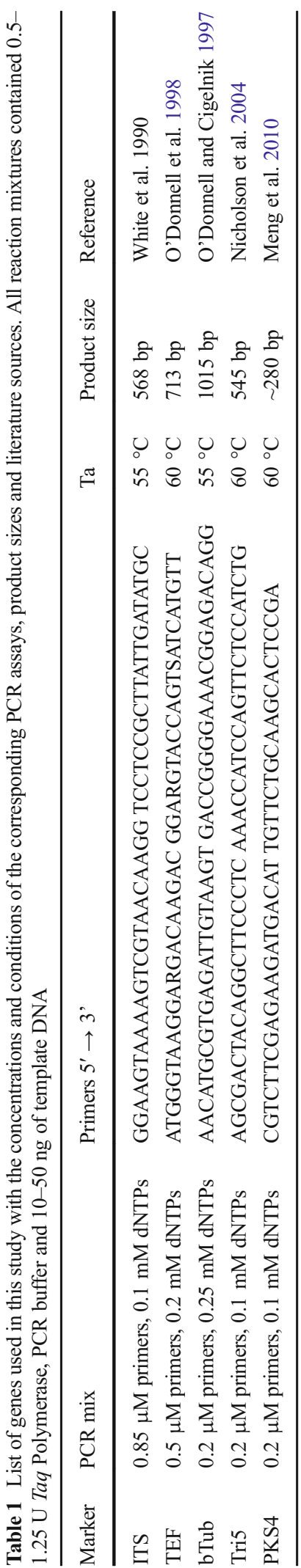


medium using the inoculation loop. The next day, single germinating spores were moved to PSA medium.

PCR and sequencing

Single-spore cultures were moved to liquid potato sucrose medium. The mature fungal colonies were transferred to $1.5 \mathrm{~mL}$ Eppendorf tubes and freeze dried. The mycelia were ground to powder using a microtube pestle, and DNA was isolated using the GenElute Plant Genomic DNA Miniprep Kit (Sigma-Aldrich, St. Louis, MO, USA) according to the manufacturer's instructions. The DNA of each isolated fungus was used for the PCR amplifications of the ITS, TEF and bTub markers for species identification (Table 1) and the amplification of markers of the ability to produce trichothecenes (Tri5) and zearalenone (PKS4). The ITS marker covers the partial $18 \mathrm{~S}, 28 \mathrm{~S}$ and complete sequence of 5.8S ribosomal RNA genes as well as full sequence of the internal transcribed spacers 1 and 2; TEF and bTub markers cover approximately $40 \%$ and $60 \%$ of corresponding genes sequences, respectively (including introns). The PCR reactions with the ITS (ITS5/ITS4), TEF (EF-1/EF-2) and bTub primers (T1/T222) were performed in $40 \mu \mathrm{L}$ and assays with Tri5 (Tri5F/ Tri5R), and the reactions with the PKS4 primers (PKS 4-2-F1/PKS 4-2-R1) were performed in $20 \mu \mathrm{L}$ reactions under the conditions presented in Table 1 . The quantities and qualities of the PCR products were examined on $1.5 \%$ agarose gels stained with ethidium bromide. The products obtained with the ITS, TEF and bTub primers were purified with a GenElute PCR Clean-Up Kit (Sigma-Aldrich, St. Louis, MO, USA) according to the manufacturer's protocol. When more than one band was present, the product of the expected size was cut out from the gel under UV light and extracted with a GenElute Gel Extraction Kit (Sigma-Aldrich, St. Louis, MO, USA). DNA sequencing was performed by an external company (Genomed S. A, Warsaw, Poland).

Phylogenetic analysis

The qualities of the retrieved sequences were evaluated with ChromasLite 2 software. The sequences obtained with the forward and reverse primers were used to prepare the consensus sequences using MultAlin online software (Corpet 1988). The sequences of ITS, tef- $1 \alpha$ and bTub from the isolates examined in this study were queried against NCBI GenBank, the Fusarium-ID
(Geiser et al. 2004) and Fusarium MLST (O'Donnell et al. 2012) databases using the megablast algorithm, BLOSUM62 matrix and pairwise sequence alignment, respectively, for the species identification. The species from which the closest matching sequences (i.e., the lowest $e$ value and the greatest identity and maximum coverage) originated were considered to be the identified species of the query.

A dataset for each isolate consisting of three gene regions was aligned using the ClustalW alignment method in MEGA6 software (Tamura et al. 2013) and trimmed manually to the same length when needed. The same software was used to analyse the phylogenetic relationships using the maximum parsimony (MP) approach with the "gaps ignore" option. The most parsimonious trees were evaluated by bootstrapping with 1000 replications. The trees were prepared with two separate input data sets. The first data set contained the combined ITS, TEF and bTub sequences of 73 Fusarium isolates with Colletotrichum gloeosporioides (MAFF237919) as outgroup. Only five F. oxysporum isolates of various origins were used in this data set because $F$. oxysporum was recovered most often and the large number of sequences of this species might have disturbed the tree readability. The second data set used for MP tree preparation consisted of multilocus sequences of $65 F$. oxysporum isolates with the MF1 F. sambucinum isolate used as outgroup.

\section{Pathogenicity tests}

Single-spore fungal cultures were grown on PSA for three weeks at $16{ }^{\circ} \mathrm{C}$. The spores were rinsed from the culture with sterile water and used to prepare the inocula. The concentration was adjusted to $2.5 \times 10^{6} / \mathrm{mL}$ using a haemocytometer.

Pathogenicity tests were performed on 119 Fusarium isolates: F. oxysporum $(N=44) ; F$. avenaceum (17); F. solani $(15) ;$ F. sambucinum $(10) ;$ F. cerealis $(7)$; $F$. culmorum, F. graminearum and $F$. tabacinum (5 isolates each); F. redolens (4); F. venenatum (3); single isolates of $F$. equiseti and F. merismoides; and two unidentified Fusarium isolates (M87A and M115). Additionally, Ilyonectria sp. and Colletotrichum sp. isolates from dry rot-infected tubers were used in tests to evaluate their potential role in the development of disease. Each test was performed with two replications. In each replication, five tubers from four potato cultivars (cvs.) were inoculated with fungal isolates. 
Table 2 List of the species identified and grouped according to their origins. The section 'other' contains three locations, i.e., Naroczyce, Świebodzin and Zazdrość, and three isolates from imported potato tubers bought in a grocery store (imported from unidentified countries)

\begin{tabular}{|c|c|c|c|c|c|c|}
\hline \multirow[t]{2}{*}{ Species } & \multicolumn{2}{|c|}{ Place of origin } & \multirow[b]{2}{*}{ Zamarte } & \multirow[b]{2}{*}{ Other } & \multirow[t]{2}{*}{ Sum } & \multirow[t]{2}{*}{$\%$ of all } \\
\hline & Młochów & Chwałowice & & & & \\
\hline F. avenaceum & 4 & & 11 & 3 & 18 & 12.1 \\
\hline F. cerealis & 2 & & 1 & 4 & 7 & 4.7 \\
\hline F. culmorum & 8 & & & & 8 & 5.4 \\
\hline F. equiseti & & & 1 & & 1 & 0.7 \\
\hline F. graminearum & 3 & & 1 & 1 & 5 & 3.4 \\
\hline F. merismoides & & & & 1 & 1 & 0.7 \\
\hline F. oxysporum & 47 & 15 & 4 & 1 & 67 & 45 \\
\hline F. redolens & 2 & 2 & 1 & & 5 & 3.4 \\
\hline F. sambucinum & 9 & & & 2 & 11 & 7.4 \\
\hline F. solani & 7 & 3 & 5 & 1 & 16 & 10.7 \\
\hline F. tabacinum & & & 4 & & 4 & 2.7 \\
\hline F. venenatum & & 1 & 2 & & 3 & 2 \\
\hline Unidentified Fusarium & 3 & & & & 3 & 2 \\
\hline \multirow[t]{2}{*}{ Sum } & 85 & 21 & 30 & 13 & & \\
\hline & \multicolumn{6}{|c|}{$\mathbf{1 4 6}$ isolates of $\mathbf{1 2}$ Fusarium species +3 unidentified } \\
\hline
\end{tabular}

Limited information on the cultivars' resistance to dry rot was available. The Hinga (starch, late) and Kuba (starch, mid-early) cultivars have been described as moderately resistant to dry rot, with a grade of 6 on a 1-9 scale, in which 9 indicates the greatest resistance (Boguszewska et al. 2011). The resistances of the cvs. Bartek (table, mid-early) and Gawin (table, mid-early) were unknown. The apical ends of the tubers were wounded with a specially prepared tool tipped with a metal cylinder to cause a wound of $10 \mathrm{~mm}$ in depth and $5 \mathrm{~mm}$ in diameter. Fifty microlitres of inoculum was pipetted into the wound and incubated for four weeks at $16^{\circ} \mathrm{C}$ in a plastic box covered with glass to maintain the humidity. To test whether the temperature affected the pathogenic capacity, a subgroup of 23 fungal isolates were tested with four replications in which two were incubated at $16{ }^{\circ} \mathrm{C}$ and two were inoculated at $20^{\circ} \mathrm{C}$. The same setup was also used to test how co-infection influenced pathogenicity. For these tests, equal amounts of spore suspensions $\left(2.5 \times 10^{6} / \mathrm{mL}\right)$ of $F$. oxysporum isolate $\mathrm{Z} 157$ were combined with other Fusarium species in the following three mixes: Mix 1 contained Z155B ( $F$. avenaceum), Mix 2 contained Z174A ( $F$. graminearum), and Mix 3 contained Z162 (F. solani). After the incubation period, the tubers were cut in half along their longer axes and two perpendicular diameters of the lesions were measured. The lesion size was calculated for each tuber as the mean of the two diameters. Statistical analyses were performed using Statistica 10 software (Statsoft Inc., 2011). Analyses of variance were performed to test the

Table 3 Fusarium spp. identified in potato dry rot samples and grouped according to the results of the PCR assays with the Tri5 and PKS4 markers to indicate the potential abilities to produce trichothecenes and zearalenone, respectively

\begin{tabular}{|c|c|c|}
\hline \multicolumn{2}{|c|}{ Product presence } & \multirow[t]{2}{*}{ Fusarium spp. } \\
\hline Tri5 & PKS4 & \\
\hline- & - & F. avenaceum, F. merismoides, F. oxysporum, F. redolens, F. solani, F. tabacinum, M87A, M115 and M93 \\
\hline+ & - & F. sambucinum and $F$. venenatum \\
\hline+ & + & F. cerealis, $F$. culmorum, $F$. equiseti and $F$. graminearum \\
\hline
\end{tabular}


effects of the species, cultivar and their interaction as well as isolate, temperature and their interaction on pathogenicity. Post-hoc Tukey tests were applied to prepare homogenous groups of Fusarium spp. according to their pathogenicities. Together, each isolate or isolate mixture was tested on five tubers of four potato cvs. in two replicates.

\section{Accession numbers}

The sequences of the ITS, tef- $1 \alpha$ and $b T u b$ genes of the strains used in this study were submitted to NCBI GenBank, and their accession numbers are listed in Supplementary Table 1 . The alignments and trees are deposited in TreeBASE (http://www.treebase.org/): accession 17,844 .

\section{Results}

Identification of the Fusarium species and mycotoxin production potential

In 2012-2014, 352 potato tubers with dry rot symptoms were collected from Chwałowice (66 tubers), Młochów (139), Naroczyce (50), Świebodzin (5), Zamarte (86), Zazdrość (3) and a local store (3). From the diseased tubers, 121 Fusarium spp. isolates were recovered and identified. An additional 25 isolates collected in 1999 (an MF1 isolate of unknown origin) and in 2011 (24 isolates collected in Młochów) were included in the analyses. Despite the use of three genes for species identification, three isolates remained unidentified (ITS acc. Nos.: M87A - KP295503, M115 - KP265344 and M93 - KP265346) because no relevant identified reference sequences were available in neither database browsed. Though the TEF sequences of M87A and M115 isolates shared around $92 \%$ similarity with an $F$. virguliformae isolate, these findings found no confirmation in either ITS or bTUB sequences. In total, 149 fungal isolates were collected (Table 2, Supplementary Table 1). Additionally, single isolates of fungal species belonging to Colletotrichum, Rhizoctonia, Ilyonectria and Alternaria genera were also recovered (data not shown). The most abundant Fusarium species, which was present at all of the surveyed locations, was F. oxysporum, with 67 isolates that comprised $45 \%$ of all of the species identified. F. oxysporum was most frequently recovered in Młochów (47 of 85 isolates) and in Chwałowice (15 of 21), where it accounted for
55 and $71 \%$ of the Fusarium populations, respectively. The dominant species in Zamarte was $F$. avenaceum, with 11 of $30(37 \%)$ isolates belonging to this species. The least frequent were $F$. merismoides and $F$. equiseti, of which only single isolates were found. The most diversified Fusarium population was in Zamarte, where nine Fusarium spp. were found, whereas only four species were identified in Chwałowice. In total, 149 ITS, $141 \mathrm{TEF}$ and $144 \mathrm{bTub}$ sequences were deposited in NCBI GenBank.

The isolates are listed in Table 3 according to their potential abilities to produce trichothecenes and zearalenone. PCR assays were applied to divide the tested Fusarium species into the following three groups: 1) species unable to produce the tested mycotoxins (both markers absent), 2) potential producers of trichothecenes only, and 3) producers of trichothecenes and zearalenone (both markers present; Table 3). No intraspecific variations in the presence of the Tri5 and PKS4 markers were detected. No species that produced only zearalenone were observed.

\section{Phylogeny}

To illustrate the relationships among the 10 Fusarium spp. from potato (73 isolates including five F. oxysporum isolates), an MP tree was constructed (Fig. 1), with a consistency index (CI) of 0.71 and a retention index (RI) of 0.95 . The phylogenetic reconstruction revealed six main clades. The trichothecene and zearalenone producers comprised clade one (F. cerealis, F. culmorum and F. graminearum; branch support value of $99 \%$ ) and shared a common ancestor with the trichothecene-only producers $F$. sambucinum and $F$. venenatum. An independent branch was formed by a single $F$. equiseti isolate that was also capable of synthesizing both of the examined mycotoxins. A separate branch was formed by the $F$. avenaceum isolates (99 \% bootstrap value). Another clade was formed by the $F$. redolens and $F$. oxysporum species. The $F$. solani isolates with two unidentified isolates (M87A and M115) were clustered together with a $99 \%$ bootstrap value. An independent branch was formed by the unidentified isolate M93.

The intraspecific diversity amongst the $F$. oxysporum isolates was investigated in a separate analysis that resulted in the MP tree shown in Fig. $2(\mathrm{CI}=0.99$, $\mathrm{RI}=0.98)$. The intraspecific variation among the 65 tested isolates appeared to be low. No clear groups 


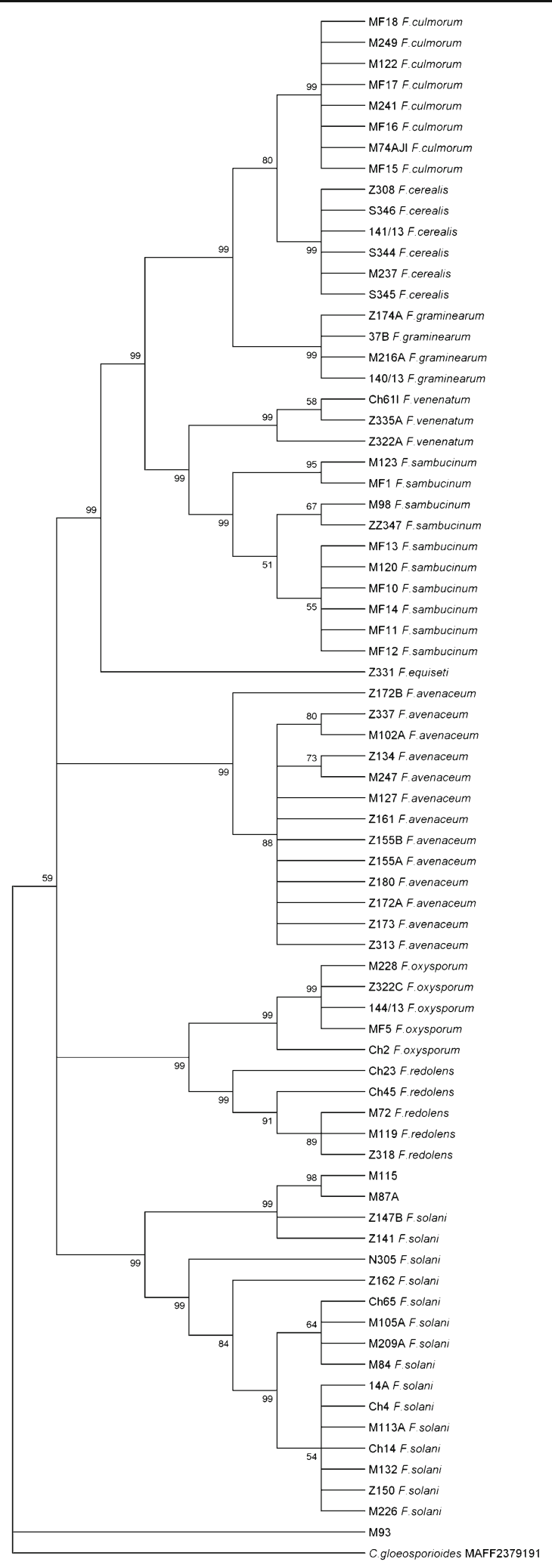

Fig. 1 Maximum parsimony tree obtained using the combined ITS, TEF and bTub sequences of 73 isolates belonging to 10 Fusarium species. The tree consisting of 1315 sites (391 parsimony-informative) was tested by bootstrapping (1000 replicates) with a cut-off value of $50 \%$. C. gloeosporioides was used as outgroup. TreeBASE accession number: 17,844

distinguishing isolates with different origins were observed. Isolate 144/13 of unknown origin exhibited no divergence and was grouped with the Polish isolates.

\section{Pathogenicity of Fusarium spp.}

An analysis of variance revealed significant influences of species, potato cultivar and the interaction of species $\times$ cultivar on the size of the lesion (Supplementary Table 2). Among the tested fungal species, F. sambucinum was the most pathogenic (Supplementary Table 3) and produced average lesions of $17.0 \mathrm{~mm}$ on the $\mathrm{cv}$. Bartek, $19.7 \mathrm{~mm}$ on cv. Gawin, $29.8 \mathrm{~mm}$ on cv. Hinga and $19.7 \mathrm{~mm}$ on cv. Kuba (10 isolates; Fig. 3). Lesion sizes less than $13 \mathrm{~mm}$ did not exceed the size of the mechanical wound; thus this size was taken as the threshold between pathogenicity and non-pathogenicity. Based on this assumption, pathogenic isolates were found for $F$. sambucinum ( $9 / 10$ isolates), F. avenaceum (2/17), F. culmorum (1/5) and F. graminearum (2/5; Supplementary Table 4$)$. The average lesion size caused by $F$. avenaceum was $10.9 \mathrm{~mm}$, whereas the two pathogenic isolates developed considerably larger lesions of 17.5 and $16.4 \mathrm{~mm}$. One F. culmorum (lesion size: $13.1 \mathrm{~mm}$ ) and two $F$. graminearum (lesions of 15.1 and $14.1 \mathrm{~mm}$ ) isolates were significantly more pathogenic than the other isolates that belonged to these species. In contrast, the majority of the $F$. sambucinum isolates were pathogenic to the potato and caused an average lesion of $21.6 \mathrm{~mm}$. Only one $F$. sambucinum isolate caused an average lesion size that was considerably lower, at $12.1 \mathrm{~mm}$ (Supplementary Table 4).

\section{Resistance of potato cultivars}

The lesion sizes on four different potato cultivars, calculated as averages from 37 isolates from four of the most pathogenic Fusarium species, are shown in Fig. 4. Cv. Gawin was the most resistant cultivar, with an average lesion size of $12.2 \mathrm{~mm}$. Cvs. Kuba and Bartek exhibited statistically similar resistance to the Fusarium spp. tested, with average lesion sizes of 13.1 and $13.7 \mathrm{~mm}$, respectively. The most susceptible cv., Hinga, exhibited an average lesion size of $17.0 \mathrm{~mm}$. 
M198 F.oxysporum

M213 F.oxysporum

M225 F.oxysporum

M233A F.oxysporum

M232 F.oxysporum

M215A F.oxysporum

M195 F.oxysporum

M217A F.oxysporum

M214 F.oxysporum

M193A F.oxysporum

M230 F.oxysporum

M79 F.oxysporum

M77 F.oxysporum

Z157 F.oxysporum

Z154 F.oxysporum

M114B F.oxysporum

M114A F.oxysporum

Ch59 F.oxysporum

Ch51 F.oxysporum

Ch43I F.oxysporum

Ch20 F.oxysporum

Ch13 F.oxysporum

Ch10 F.oxysporum

Ch6 F.oxysporum

M256 F.oxysporum

M238 F.oxysporum

M220 F.oxysporum

3 M126 F.oxysporum

M194B F.oxysporum

Ch2 F.oxysporum

Ch24 F.oxysporum

Ch40 F.oxysporum

96

Ch52 F.oxysporum

M81A F.oxysporum

47B F.oxysporum

M207 F.oxysporum

Z163 F.oxysporum

M240 F.oxysporum

M194A F.oxysporum

M248B F.oxysporum

62

M188 F.oxysporum

5A F.oxysporum

36A F.oxysporum

501 F.oxysporum

50Jl F.oxysporum

2 M200 F.oxysporum

6A F.oxysporum

M197 F.oxysporum

M239 F.oxysporum

M187 F.oxysporum

62B F.oxysporum

MF1 F. sambucinum 
Fig. 2 Maximum parsimony tree created for the combined ITS, TEF and bTub sequences of 65 isolates of $F$. oxysporum. The tree consists of 1445 sites, of which 10 were parsimony informative. Bootstrap support values $>50 \%$ are shown at the nodes. The names of the isolates encode their places of origin: $\mathrm{Ch}-$ Chwałowice; M, MF or numbers only - Młochów; Z - Zamarte; and imported isolate $144 / 13$. TreeBASE accession number: 17,844

Influence of temperature on pathogenicity

The pathogenicities of 23 isolates of 5 Fusarium species, 1 isolate of Ilyonectria sp. and three mixtures of isolates of Fusarium spp. were tested at $20^{\circ} \mathrm{C}$ and $16^{\circ} \mathrm{C}$. The average lesion sizes after incubation at both temperatures were compared, and the results are shown in Fig. 5. The analysis of variance revealed that temperature, isolate and the temperature $\times$ isolate interaction exerted significant effects on the lesion size ( $p=0.005$; Supplementary Table 5). Post-hoc Tukey tests revealed significant differences between the tested temperatures and indicated that $16^{\circ} \mathrm{C}$ (mean lesion size: $10.8 \mathrm{~mm}$ ) was a more suitable incubation temperature than $20^{\circ} \mathrm{C}$ for disease progression (mean lesion size: $10.1 \mathrm{~mm}$ ). However, three of the isolates were more pathogenic at $20{ }^{\circ} \mathrm{C}$, i.e., Z173, Z155B (F. avenaceum), and Z162 (F. graminearum), as were the isolates in mixes 1 ( $F$. oxysporum + $F$. avenaceum) and 2 (F. oxysporum $+F$. graminearum $)$.

\section{Discussion}

ITS sequences are frequently used to identify fungal species, and vast numbers of these sequences are already available in databases. However, as reported by O'Donnell and Cigelnik (1997), the existence of nonorthologous copies of these sequence in some clades may lead to erroneous phylogenies. Errors that resulted in incorrect annotations of some ITS sequences may have been propagated over time in the databases (Nilsson et al. 2014). Hence, in addition to ITS, we sequenced fragments of two genes, i.e., the single-copy translation elongation factor 1- $\alpha$ (TEF) gene, which typically displays a high level of sequence polymorphism (O'Donnell et al. 1998), and $\beta$-tubulin (O'Donnell and Cigelnik 1997). Multilocus sequence fragments consisting of these three genes (i.e., ITS, tef-1 $\alpha, b T u b$ ) were analysed to resolve the relationships among the species and to provide information regarding the intraspecific variation. Among the 12 recovered species, eight ( $F$. avenaceum, $F$. cerealis, $F$. culmorum, F. equiseti, F. graminearum, $F$. oxysporum, F. sambucinum and $F$. solani) were in the group that has been globally associated with dry rot in potatoes (Cullen et al. 2005), and two (F. merismoides and $F$. redolens) had previously been reported to be pathogenic to potatoes (Førsund 1980; Salami and Popoola 2007). No reports on the pathogenicities of

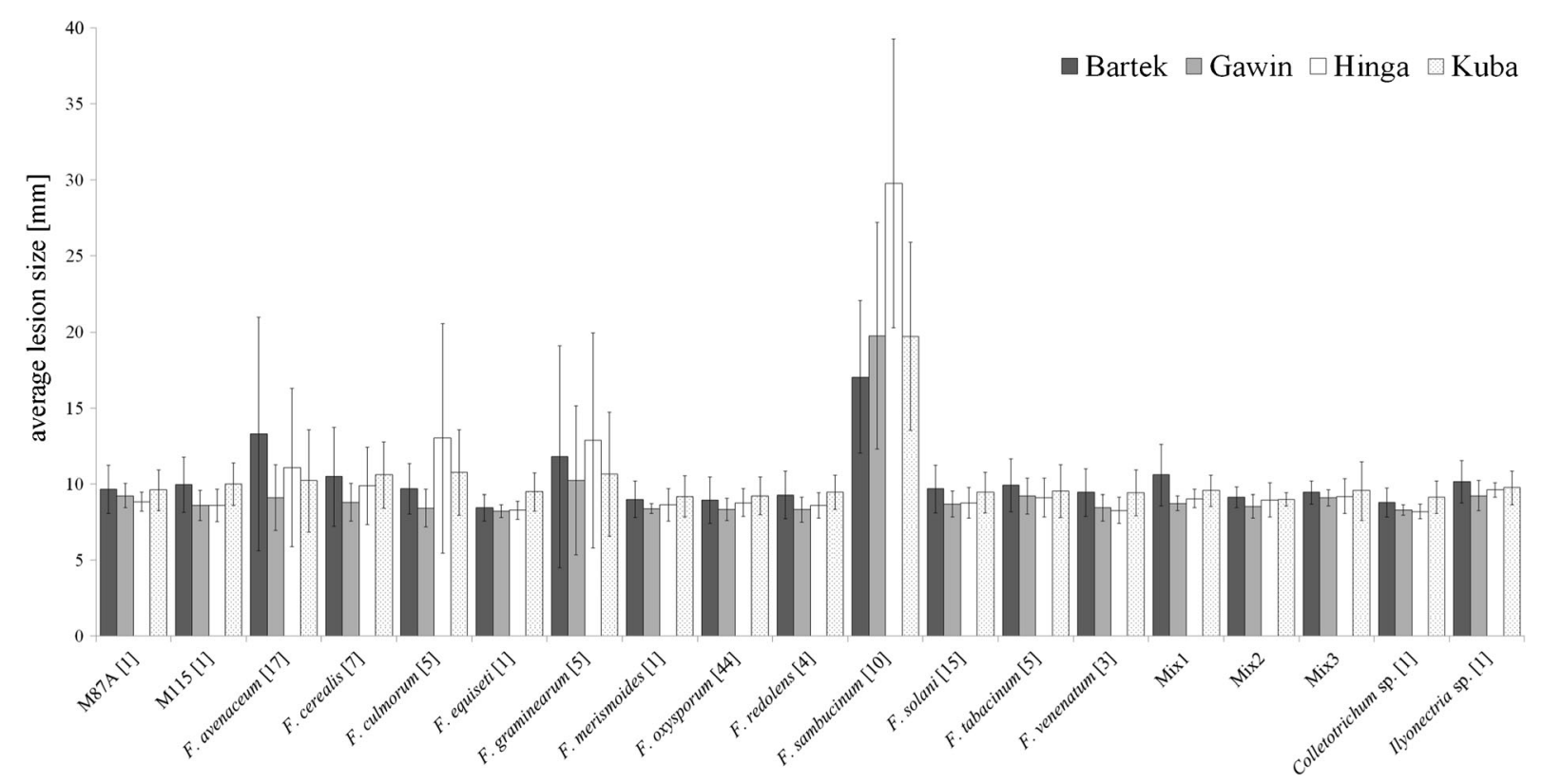

Fig. 3 Pathogenicity test results shown as the average lesion sizes caused by the tested fungal species on four potato cultivars. The numbers of isolates representing a given species are shown in brackets. The standard deviations are indicated by the error bars 


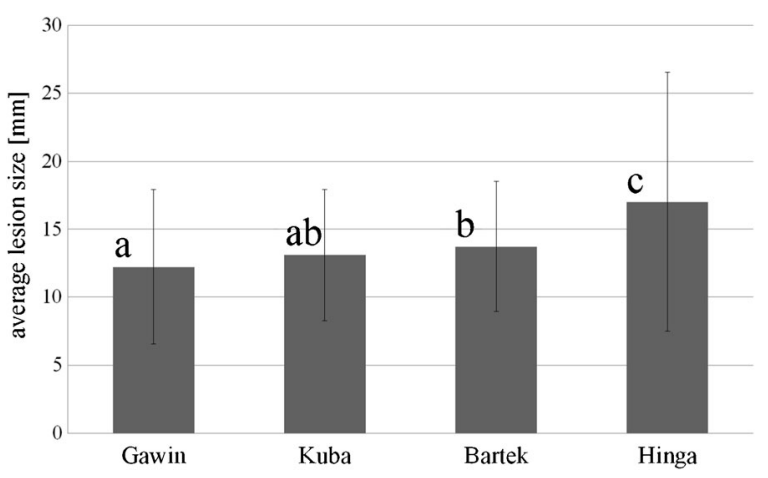

Fig. 4 The average lesion sizes calculated for all $37 \mathrm{~F}$. avenaceum, $F$. culmorum, F. graminearum and F. sambucinum isolates in four potato cultivars used in pathogenicity tests at $16^{\circ} \mathrm{C}$. Values marked with the same letters were not significantly different from each other according to Tukey's post-hoc tests. The standard deviations are shown as the error bars

F. venenatum or F. tabacinum have been published; however, the latter was isolated in large numbers from potato roots (Scholte et al. 1985).

Analyses were performed with 73 isolates of 10 Fusarium species (Fig. 1). The resulting phylogenetic relationships remained in agreement with previous studies (Du et al. 2012; Kristensen et al. 2005; Zhang et al. 2006). The isolates of the same species were grouped together in the resulting MP tree, supporting their correct identification. Fusarium culmorum, F. cerealis and
F. graminearum formed monophyletic groups with strong support of $99 \%$ bootstrap values. The species that belong to this clade are potentially trichothecene and zearalenone producers and formed a sister clade to a clade comprising $F$. sambucinum and $F$. venenatum; these latter species produced only trichothecenes (each species was supported by a $99 \%$ bootstrap value). A distinct branch was formed by $F$. equiseti, which was a trichothecene and zearalenone producer. These results agree with those of previous studies (Kristensen et al. 2005) suggesting that the ancestor of the three clades described above gained the abilities to synthesize trichothecenes and zearalenone. The zearalenone-producing capacity was then lost in the clade formed by $F$. sambucinum and $F$. venenatum. A separate branch was formed by $F$. avenaceum (99 \% bootstrap value). Among the isolates from that species, some sub-lineages were formed; however, these sub-lineages were not distinguished according to their geographic origins. Five isolates of different origins were chosen to represent the F. oxysporum species. Only one, $\mathrm{Ch} 2$, formed a separate branch, and the remaining four clustered together. Similarly, the isolates $\mathrm{Ch} 23$ and $\mathrm{Ch} 45$ formed separate branches in the $F$. redolens clade. Two unidentified isolates, i.e., M115 and M87A, grouped within the F. solani clade, and they most likely belonged to the F. solani species complex (FSSC). Multilocus sequence

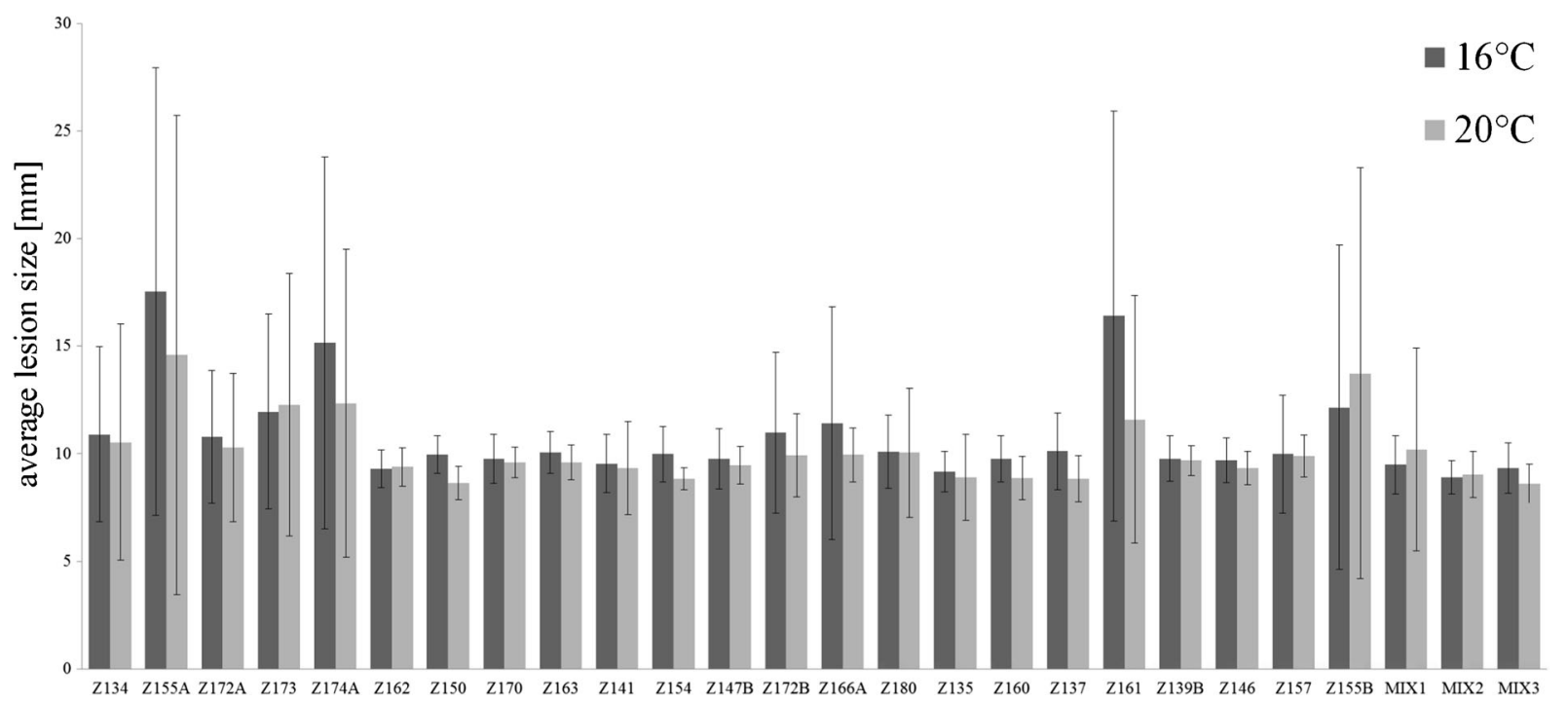

Fig. 5 Average lesion sizes of the isolates incubated at two temperatures. Standard deviations are shown as error bars. F. avenaceum: Z134, Z155A, Z172A, Z173, Z172B, Z166A, Z180, Z161, and Z155B; F. graminearum: Z174A; F. solani: Z162, Z150, Z141, Z147B, and Z135; F. tabacinum: Z170, Z160, Z137, and Z139B;
F. oxysporum: Z163, Z154, and Z157; Ilyonectria sp.: Z146.; Mix 1: $\mathrm{Z} 157+\mathrm{Z} 155 \mathrm{~B}(F$. oxysporum $+F$. avenaceum $)$; Mix 2: $\mathrm{Z} 157+\mathrm{Z174A}(F$. oxysporum $+F$. graminearum $)$; and Mix 3: $\mathrm{Z} 157+\mathrm{Z} 162($ F. oxysporum + F. solani $)$ 
analyses (Zhang et al. 2006) have revealed the existence of over 45 species belonging to the FSSC that had previously been identified as $F$. solani due to these species' morphological similarities. A high level of diversity of the $F$. solani isolates was also detected in our study, supporting the idea that these isolates are members of the FSSC rather than a single species. The M115 and M87A isolates shared similar levels of pathogenicity as the $F$. solani isolates, as shown in our tests. In an additional analysis (data not shown), the tef- $1 \alpha$ sequences of $F$. solani isolates from this study were analysed along with sequences deposited in the NCBI GenBank database under $F$. solani and $F$. solani var. coeruleum (syn. F. coeruleum) species names. The results revealed a strong resemblance between the first two groups of sequences, whereas $F$. coeruleum differed notably. Hence, we conclude that the isolates collected in our study were $F$. solani. The unidentified isolate M93 appeared to be distinct from the other species included in this study, and the divergence appears to have occurred early (Fig. 1). Its TEF and ITS sequences shared a high level of similarity with a CBS 119875 strain described as Fusarium of unknown species. Further morphological analyses should be performed to identify this isolate to the species level.

Fusarium species can be passively dispersed via the atmosphere; however, because of their abundance in the soil, they are often referred to as soil borne, and F. oxysporum has been reported to be the most common Fusarium in the soil (Nelson et al. 1981). In the sampled potatoes with dry rot symptoms, $45 \%$ of all of the isolates were identified as F. oxysporum; however, none of the tested isolates of this species were pathogenic to the potato tubers in our study, or they were at least unable to cause dry rot under the tested conditions. Manici and Cerato (1994) showed that of the 8 F. oxysporum isolates tested, all were pathogenic to potato tubers when incubated at $20^{\circ} \mathrm{C}$. Hence, we tested the pathogenicities of three isolates of $F$. oxysporum and some other species following exposure to two different temperatures $\left(16^{\circ} \mathrm{C}\right.$ and $\left.20^{\circ} \mathrm{C}\right)$. An analysis of variance showed that the temperature exerted a significant influence on the lesion size, with the average lesions formed at $16{ }^{\circ} \mathrm{C}$ larger than those formed at $20{ }^{\circ} \mathrm{C}$; however, none of the $F$. oxysporum isolates displayed enhanced pathogenicity with increased temperature. Incubation at $20{ }^{\circ} \mathrm{C}$ was more favourable for two of the $F$. avenaceum and one of the $F$. solani isolates and for $F$. avenaceum and $F$. graminearum when mixed with $F$. oxysporum.
The effect of temperature on disease development differed among the species and among the isolates of the same species. These findings might explain why our results contradict those of Manici and Cerato (1994).

The frequent presence of $F$. oxysporum in sampled dry rot lesions might be explained by another hypothesis that this species infects the tuber either together with some other, more pathogenic species or after the tissue has already been attacked by other pathogens. According to the literature, fungal species that simultaneously infect the same host can interact with each other. For example, Velluti et al. (2000) reported decreases in the colony forming units of $F$. verticillioides and $F$. proliferatum when they co-infected maize kernels together with $F$. graminearum. Such interactions have also been observed in another experiment (Tajrin 2013), in which eight oat genotypes were inoculated with $F$. graminearum and $F$. langsethiae together and separately. Stronger $F$. graminearum growth, as measured by the amount of fungal DNA, was reported on six of the oat genotypes with which $F$. graminearum was co-infected along with $F$. langsethiae compared to inoculation with $F$. graminearum alone. These results may be explained by either possible competition between species attacking the same host, leading to the increased growth of one or the other species, or a synergistic interaction between species (Tajrin 2013). Xu et al. (2007) observed a negative effect of co-infection in an experiment in which wheat ears were inoculated separately or with combinations of two or three isolates of $F$. avenaceum, F. culmorum, $F$. graminearum and $F$. poae. The co-inoculations led to decreases in fungal biomass compared the single-isolate inoculations, and the single inoculations also exhibited 1000 -fold greater nivalenol production. In our experiment, we used three mixtures of $F$. oxysporum with $F$. avenaceum, $F$. graminearum or $F$. solani to inoculate potato tubers. These co-infections did not enhance the pathogenicities of any of the isolates compared to the single inoculations. Interestingly, the use of isolate Z174A of $F$. graminearum in Mix 2 even decreased its pathogenicity. Concentrations of mycotoxins should be measured to determine whether this isolate shifted its energy allocation to produce more toxins at the expense of pathogenicity. Low pathogenicities of the abundant F. oxysporum isolates might indicate that we did not isolate a dry rot causal agent but, rather, a contaminant from soil because this species is very abundant and is adapted to long-term survival in the soil (Nelson et al. 1981). Another possibility is that the F. oxysporum 
isolates were secondary colonizers in the dry rot-infected potato tubers because $F$. oxysporum has also been reported to be a vigorous saprophyte (Nelson et al. 1981).

Twelve Fusarium species were identified in rotten potato samples in this study and may have caused contamination with mycotoxins other than the expected mycotoxins based on the typical dry rot-causing Fusarium species. F. equiseti and $F$. oxysporum were isolated; therefore, potential risks of contamination with beauvericin, moniliformin and fumonisins $\mathrm{B}_{1}$ (Stępień 2013) along with zearalenone and trichothecenes exist in potato tubers. Depending on a population structure resulting from a survey, a range of mycotoxins might be anticipated and further research for their presence carried out. Even in this relatively small sample of 149 isolates, we found three samples that were unidentifiable based on the existing nucleotide sequence databases, which indicates that the knowledge of Fusarium spp. in the potato is limited and requires further study. The large group of F. oxysporum isolates recovered that were not obviously pathogenic in the laboratory tests might still be pathogenic in the field and in storage. These isolates might be secondary pathogens or might require specific environmental factors that were not reproduced in the laboratory to cause infection. Less abundant but definitely pathogenic were F. sambucinum, F. avenaceum, F. culmorum and $F$. graminearum, and these results are in accordance with those of earlier reports (Peters et al. 2008b; Du et al. 2012). In our study, statistical analysis performed on the four of pathogenic Fusarium spp. divided the isolates according to their pathogenicity (Supplementary Table 4). High number $(90.6 \%)$ of the recovered isolates caused lesions of size below the threshold which may be puzzling. The range of a lesion size between 1.3 and $351.4 \mathrm{~mm}^{2}$ caused by the $F$. cerealis isolates in the study of Gachango et al. (2012) indicates that among the 17 tested isolates some would be considered non-pathogenic in our tests, since the lesion would not significantly exceed the size of a mechanical wound. Large ranges in a disease development capabilities of different Fusarium spp. were also reported in other studies (Choiseul et al. 2007; Peters et al. 2008a; Peters et al. 2008b).

The main agents that cause dry rot in potato tubers differ depending on location, but might also change over time, particularly under conditions of climate change. The data from our survey can serve for monitoring Fusarium spp. in potato. Knowing which Fusarium spp. are present in the potato tubers with dry rot could help minimizing crop losses and mycotoxin contamination by fungicide application, since the resistance to fungicides might differ in frequency among isolates of different species (Peters et al. 2008a). Moreover, the acquired data may be helpful for planning a crop rotation, but also a crop in the vicinity of the area surveyed. Some of the Fusarium spp. we have isolated from potato tubers are known to be important cereal pathogens and growing such cereal host species before or next to potatoes should be avoided to limit the risk of dry rot of potato tubers.

Acknowledgments The Polish National Centre for Research and Development financed this work within the JPI FACCE project Modelling European Agriculture with Climate Change for Food Security, grant number: FACCE JPI/02/2012 NCBiR. The authors thank Łukasz Stęień from the Institute of Plant Genetics, Polish Academy of Sciences, for valuable advice and comments, as well as Piotr Kamiński from the Potato Breeding Zamarte Ltd. - IHAR Group and Krystyna Michalak and Beata Tatarowska from the Plant Breeding and Acclimatization Institute - National Research Institute for tuber samples.

Open Access This article is distributed under the terms of the Creative Commons Attribution 4.0 International License (http:// creativecommons.org/licenses/by/4.0/), which permits unrestricted use, distribution, and reproduction in any medium, provided you give appropriate credit to the original author(s) and the source, provide a link to the Creative Commons license, and indicate if changes were made.

\section{References}

Baturo-Cieśniewska, A., \& Suchorzyńska, M. (2011). Verification of the effectiveness of SCAR (Sequence Characterized Amplified Region) primers for the identification of Polish strains of Fusarium culmorum and their potential ability to produce B-trichothecenes and zearalenone. International Journal of Food Microbiology, 148, 168-176.

Baturo-Cieśniewska, A., Lenc, L., Grabowski, A., \& Łukanowski, A. (2014). Characteristics of Polish isolates of Fusarium sambucinum: molecular identification, pathogenicity, diversity and reaction to control agents. American Journal of Potato Research. doi:10.1007/s12230-014-9410-z.

Boguszewska, D., Czerko, Z., Goliszewski, W., Grudzińska, M., Lutomirska, B., Nowacki, W., Szutkowska, M., Trawczyński, C., Wierzbicka, A., Zarzyńska, K., Zgórska, K. (2011). Charakterystyka Krajowego Rejestru Odmian Ziemniaka. Nowacki W. (Ed.). IHAR-PIB, Oddział Jadwisin: 1-40

Chełkowski, J. (1989). Toxigenicity of Fusarium species causing dry rot of potato tubers. In: Chelkowski (Ed.) Fusarium Mycotoxins, Taxonomy and Pathogenicity. Elsevier Science Publishing Co., Inc., New York. 435-40

Choiseul, J., Allen, L., \& Carnegie, S. (2007). Fungi causing dry tuber rots of seed potatoes in storage in Scotland. Potato Research, 49, 241-253. 
Corpet, F. (1988). Multiple sequence alignment with hierarchical clustering. Nucleic Acids Research, 16(22), 10881-10890.

Cullen, D. W., Toth, I. K., Pitkin, Y., Boonham, N., Walsh, K., Barker, I., \& Lees, A. K. (2005). Use of quantitative molecular diagnostic assays to investigate Fusarium dry rot in potato stocks and soil. Phytopathology, 95, 1462-1471.

Du, M., Ren, X., Sun, Q., Wang, Y., \& Zhang, R. (2012). Characterization of Fusarium spp. causing potato dry rot in China and susceptibility evaluation of Chinese potato germplasm to the pathogen. Potato Research, 55, 175-184.

FAOSTAT (2014) [http://faostat3.fao.org/] Accessed 15 March 2015

Førsund, E. (1980). Tuber dry rot caused by Fusarium merismoides Cda. Potato Research, 23, 478.

Gachango, E., Hanson, L. E., Rojas, A., Hao, J. J., \& Kirk, W. W. (2012). Fusarium spp. causing dry rot of seed potato tubers in Michigan and their sensitivity to fungicides. Plant Disease, 96, 1767-1774.

Geiser, D., del Mar Jiménez-Gasco, M., Kang, S., Makalowska, I., Veeraragha, v. N., Ward, T., Zhang, N., Kuldau, G., \& O’Donnell, K. (2004). Fusarium-ID v. 1.0: a DNA sequence database for identifying Fusarium. European Journal of Plant Pathology, 110, 473-479.

Geiser, D. M., Aoki, T., Bacon, C. W., Baker, S. E., Bhattacharyya, M. K., et al. (2013). LETTER TO THE EDITOR: One fungus, one name: Defining the genus Fusarium in a scientifically robust way that preserves longstanding use. Phytopathology, 103, 400-408.

Hanson, L. E., Schwager, S. J., \& Loria, R. (1996). Sensitivity to thiabendazole in Fusarium species associated with dry rot of potato. Phytopathology, 86, 378-384.

Kim, J. C., \& Lee, Y. W. (1994). Sambutoxin, a new mycotoxin produced by toxic Fusarium isolates obtained from rotted potato tubers. Applied and Environmental Microbiology, 60, $4380-4386$.

Kristensen, R., Torp, M., Kosiak, B., \& Holst-Jensen, A. (2005). Phylogeny and toxigenic potential is correlated in Fusarium species as revealed by partial translation elongation factor 1 alpha gene sequences. Mycological Research, 109, 173-186.

Latus-Ziętkiewicz, D., Perkowski, J., \& Chełkowski, J. (1987). Fusarium species and pathogens of potato tubers during storage and their ability to produce mycotoxins. Mycotoxins Research, Special Edition, European Seminar "Fusarium-Mycotoxins taxonomy, pathogenicity". Warsaw, 1987, 99-104.

Manici, L. M., \& Cerato, C. (1994). Pathogenicity of Fusarium oxysporum f. sp. tuberosi isolates from tubers and potato plants. Potato Research, 37, 129-134.

Mateo, J. J., Mateo, R., \& Jiménez, M. (2002). Accumulation of type A trichothecenes in maize, wheat and rice by Fusarium sporotrichioides isolates under diverse culture conditions. International Journal of Food Microbiology, 72, 115-123.

Meng, K., Wang, Y., Yang, P., Luo, H., Bai, Y., Shi, P., Yuan, T., Ma, R., \& Yao, B. (2010). Rapid detection and quantification of zearalenone-producing Fusarium species by targeting the zearalenone synthase gene PKS4. Food Control, 21, 207-211.

Nelson, P. E., Toussoun, T. A., \& Cook, R. J. (Eds.) (1981). Fusarium: diseases, biology and taxonomy. USA: The Pennsylvania State University Press.
Nicholson, P., Simpson, D. R., Wilson, A. H., Chandler, E., \& Thomsett, M. (2004). Detection and differentiation of trichothecene and enniatin-producing Fusarium species on small-grain cereals. European Journal of Plant Pathology, 110, 503-514.

Nilsson, R.H., Hyde, K.D., Pawłowska, J., Ryberg, M., Tedersoo, L., Aas, A.B., Alias, S.A., Alves, A., Anderson, C.A., Antonelli, A., Arnold, A.E., Bahnmann, B., Bahram, M., Palme, J.B., Berlin, A., Branco, S., Chomnunti, P., Dissanayake, A.J., Drenkhan, R., Friberg, H., Frøslev, T.G., Halwachs, B., Hartmann, M., Henricot, B., Jayawardena, R.S., Jumpponen, A., Kauserud, H., Koskela, S., Kulik, T., Liimatainen, K., Lindahl, B.D., Lindner, D., Liu, J.K., Maharachchikumbura, S., Manamgoda, D., Martinsson, S., Neves Niskanen, T., Nylinder, S., Pereira, O.L., Pinho, D.B., Porter, T.M., Queloz, V., Riit, T., García, M.S., de Sousa, F., Stefańczyk, E., Tadych, M., Takamatsu, S., Tian, Q., Udayanga, D., Unterseher, M., Wang, Z., Wikee, S., Yan, J.Y., Larsson, E., Larsson, K.H., Kõljalg, U., Abarenkov, K. (2014). Improving ITS sequence data for identification of plant pathogenic fungi. Fungal Diversity 67:11-19

O’Donnell, K., \& Cigelnik, E. (1997). Two divergent intragenomic rDNA ITS2 types within a monophyletic lineage of the fungus Fusarium are nonorthologous. Molecular Phylogenetics and Evolution, 7, 103-116.

O’Donnell, K., Kistler, H. C., Cigelnik, E., \& Ploetz, R. C. (1998). Multiple evolutionary origins of the fungus causing Panama disease of banana: concordant evidence from nuclear and mitochondrial gene genealogies. Proceedings of the National Academy of Sciences, 95, 2044-2049.

O’Donnell, K., Humber, R. A., Geiser, D. M., Kang, S., Park, B., Robert, V. A., Crous, P. W., Johnston, P. R., Aoki, T., Rooney, A. P., \& Rehner, S. A. (2012). Phylogenetic diversity of insecticolous fusaria inferred from multilocus DNA sequence data and their molecular identification via FUSARIUM-ID and Fusarium MLST. Mycologia, 104, 427-445.

Peters, J. C., Lees, A. K., Cullen, D. W., Sullivan, L., Stroud, G. P., \& Cunnington, A. C. (2008a). Characterisation of Fusarium spp. responsible for causing dry rot of potato in Great Britain. Plant Pathology, 57, 262-271.

Peters, R. D., MacLeod, C., Seifert, K. A., Martin, R. A., Hale, L. R., Grau, C. R., \& MacInnis, S. (2008b). Pathogenicity to potato tubers of Fusarium spp. isolated from potato, cereal and forage crops. American Journal of Potato Research, 85, 367-374.

Salami, A. O., \& Popoola, O. O. (2007). Thermal control of some post-harvest rot pathogens of Irish potato (Solanum tuberosum L.). Journal of Agricultural Science, 52, 17-31.

Scholte, K., Veenbaas-Rijks, J. W., \& Labruyère, R. E. (1985). Potato growing in short rotations and the effect of Streptomyces spp., Colletotrichum coccodes, Fusarium tabacinum and Verticillum dahliae on plant growth and tuber yield. Potato Research, 28, 331-348.

StatSoft Inc. (2011) STATISTICA (data analysis software system), version 10. Available from: www.statsoft.com

Stępień, Ł., Gromadzka, K., \& Chełkowski, J. (2012). Polymorphism of mycotoxin biosynthetic genes among Fusarium equiseti isolates from Italy and Poland. Journal of Applied Genetics, 53, 227-236.

Stepien, Ł. (2013). The use of Fusarium secondary metabolite biosynthetic genes in chemotypic and phylogenetic studies. Critical Reviews in Microbiology, 402, 176-185. 
Tajrin, T. (2013). Interaction between mycotoxin producing Fusarium species in different oat cultivars. Second cycle, A2E. Uppsala: (NL, NJ) > Dept. of Crop Production Ecology <http://stud.epsilon.slu.se/view/ divisions/4075.html>

Tamura, K., Stecher, G., Peterson, D., Filipski, A., \& Kumar, S. (2013). MEGA6: molecular evolutionary genetics analysis version 6.0. Molecular Biology and Evolution, 30, 2725-2729.

Theron, D. J. (1991). Prediction of potato dry rot based on the presence of Fusarium in soil adhering to tubers at harvest. Plant Disease, 75, 126-130.

Velluti, A., Marin, S., Bettucci, L., Ramos, A. J., \& Sanchis, V. (2000). The effect of fungal competition on colonization of maize grain by Fusarium moniliforme, $F$. proliferatum and $F$. graminearum and on fumonisin B-1 and zearalenone formation. International Journal of Food Microbiology, 59, 59-66.

Xu, X. M., Monger, W., Ritieni, A., \& Nicholson, P. (2007). Effect of temperature and duration of wetness during initial infection periods on disease development, fungal biomass and mycotoxin concentrations on wheat inoculated with single, or combinations of, Fusarium species. Plant Pathology, 56, 943956.

Xue, H. L., Yang, B., Tang, Y. M., Ying, Z., \& Yi, W. (2014). Effect of cultivars, Fusarium strains and storage temperature on trichothecenes production in inoculated potato tubers. Food Chemistry, 151, 236-242.

Zarzycka, H. (2001). Assessment of potato tuber resistance against soft rot and dry rot. In: E. Zimoch-Guzowska, J. Syller, M. Sieczka (Eds.), The methods of evaluation and selection applied in potato research and breeding. Plant Breeding and Acclimatization Institute, Radzików. Monografie i Rozprawy Naukowe IHAR 10a:88-9

Zhang, N., O’Donnell, K., Sutton, D. A., Nalim, F. A., Summerbell, R. C., Padhye, A. A., \& Geiser, D. M. (2006). Members of the Fusarium solani species complex that cause infections in both humans and plants are common in the environment. Journal of Clinical Microbiology, 44, 2186-2190. 